\title{
Counterfeit and substandard quality of drugs: The need for an effective and stringent regulatory control in India and other developing countries
}

One of the latest threats facing the global pharmaceutical industry and healthcare is the presence of spurious/substandard drugs in the market. The World Health Organization (WHO) estimates that counterfeit drugs account for approximately 5$8 \%$ of the total worldwide trade in pharmaceuticals. ${ }^{[1]}$ According to the WHO, 'a counterfeit drug is one which is deliberately and fraudulently mislabeled with respect to identity, composition, and/or source.' This definition of counterfeit includes not only completely fake drugs but also those that have been tampered with, adulterated, diluted, repackaged, or relabeled so as to misrepresent the dosage, origin, or expiration date, as well as those substandard drugs that are cheaply produced in order to make unlawful profits. The Center for Medicine in the Public Interest (USA) estimates that sales in counterfeit pharmaceuticals will reach US \$75 billion in 2010 .

Reports show that substandard drugs are available in the market worldwide. These reports are not only from the poor or developing countries but also from the developed world. However, this problem is much more severe in developing countries than in countries such as the US, UK, Canada, and other industrialized countries. In 2000, the health ministry in Russia reported that 56 drugs were counterfeit. The following year, approximately $3.6 \%$ of all pharmaceuticals in Russia were found to be fake. ${ }^{[2]}$ The United States Food and Drug Administration (US FDA) reported that in spite of stringent controls, the number of cases of counterfeit drugs had increased in 2001 compared to the number of cases five years earlier. ${ }^{[3]}$

There have always been doubts regarding the quality of the drugs available in the developing countries. ${ }^{[4]}$ Reports of treatment failure and drug resistance are frequent, ${ }^{[5-7]}$ and this is probably because of the use of substandard/counterfeit drugs in African and Asian countries. The other possible reasons could be the drugs' chemical instability, inappropriate storage and transport, and poor quality control during manufacturing. The quality of some pharmaceutical products that are exported to the least developed countries do not even meet basic quality standards. In a random quality testing in Nigeria, $48 \%$ of the samples of different categories of drug products were found to be outside the British Pharmacopoeia (BP) limits for drug assay. Out of these, some drug products were even lacking in the active ingredient. Almost $40 \%$ of these drug products were manufactured in India. ${ }^{[8]}$ In the recent past, the WHO has withdrawn the AIDS drugs manufactured by an Indian pharmaceutical company from the list when they found that the Contract Research Organization (CRO) that carried out the clinical study was not properly regulated as per the WHO standards. ${ }^{[9]}$
A study carried out in Nigeria, found that only three out of the eight brands of sulfadoxine-pyrimethamine tablets passed all BP quality specifications and were physically and chemically equivalent. ${ }^{[10]}$ There have been several reports of substandard artesunate in South East Asia. From 104 samples of artesunate taken from South East Asian countries, including Myanmar (Burma), Cambodia, Vietnam, Laos, and Thailand, 39 (38\%) were counterfeit and $30(29 \%)$ contained no artesunate at all. ${ }^{[11]}$ A recent WHO report provides information regarding the origin of counterfeit drugs in South East Asian countries. According to this study, Cambodia, China, Lao People's Democratic Republic, and Thailand have the largest number of illegal pharmaceutical vendors, unapproved pharmaceuticals, and illegal pharmaceutical manufacturers. ${ }^{[12]}$ Interestingly, China and India are the leaders in counterfeit drug production and most of the bulk active ingredients produced by China and India are used in the manufacture of counterfeit pharmaceuticals worldwide. ${ }^{[1]}$

In 1999, the WHO published extensive guidelines to combat counterfeit drugs. ${ }^{[13]}$ Recently WHO has suggested a rapid alert system for the relevant authorities in Asian countries to combat the global threat posed by counterfeit pharmaceuticals. ${ }^{[14]}$ In 2004, a workshop was organized by the International Conference of Drug Regulatory Authorities (ICDRA) in conjunction with the Spanish Medicines Agency, with its main focus on combating counterfeit pharmaceuticals. Approximately 100 participants from several national drug regulatory authorities, nongovernmental organizations, international organizations, industry associations, and media personnel participated and expressed their opinions on national and international perspectives. ${ }^{[15]}$ The need of the hour is to ensure the quality of the products being manufactured for consumption within the country or for export to other countries. WHO is planning to launch a task force to fight counterfeit drugs, vaccines, and other medical products. This task force will focus on increasing the awareness regarding counterfeit drugs and motivating consumers to report suspected counterfeit products. The International Medical Products Anti-Counterfeiting Task Force is looking to stop the trade in fake drugs, which kills thousands of people every year. ${ }^{[16]}$

Official government agencies, international bodies, and academia in Asian and African countries have always been aware of the availability of counterfeit pharmaceuticals. However, the data on counterfeit pharmaceuticals in India is only made available through the official government source. India has approximately 20,000 small manufacturing units that produce and supply pharmaceuticals at low cost. A survey conducted in 
the states of Maharashtra and Uttar Pradesh by a government agency revealed some interesting facts: (1) according to about $70 \%$ of patients, pharmacists/chemists suggest substitute pharmaceuticals in case a prescribed pharmaceutical is not available; (2) around 78\% of patients opined that chemists/ pharmacists do not inform patients about such substitutions; (3) $43 \%$ of doctors accept that there are incidents of spurious/ substandard drugs being sold in the market; (4) generic drugs from different manufacturers are available with differences of as much as $500 \%$ in prices; (5) inadequate quality checking by the respective drug authorities, poor drug awareness, and low literacy rates are the reasons being attributed for the flourishing market in spurious/ substandard drugs. ${ }^{[17]}$

One of the landmarks in the fight against counterfeit/ substandard drugs in India was the Mashelkar Committee Report in 2003. This is a comprehensive report that made proposals to upgrade the Indian drug regulatory standards and guidelines to international standards and to tackle the problem of counterfeit/substandard drugs. On the basis of the cases analyzed by various state government regulatory authorities, $0.5 \%$ drugs have been reported to be spurious and, according to initial reports, approximately $10 \%$ are of substandard quality. According to a WHO report, India leads the Asian countries by producing 35\% of Asia's counterfeit/substandard drugs. ${ }^{[18]}$ Whatever be the actual figure, it is a fact that in India there is a large amount of such drugs present in the market. The main reasons which have been put forward for this are inadequacies in drug testing, severe shortage of regulatory inspectors, corruption, and lack of law enforcement.

The Mashelkar Committee has made two important recommendations: (1) strict vigilance must be maintained, with regular surprise checks at pharmacies and for the cause checks (suspicious checks) and (2) provision of quality testing facilities for pharmaceuticals. ${ }^{[17]}$ Regular drug sample testing exercises also helps in identifying the incidence of counterfeits.

One of the major recommendations is with regard to the need for improving the drug testing facilities at the state and federal level. Adequate infrastructure is required to test pharmaceuticals. Only 15 Indian states have functional drug testing laboratories, out of which only seven are adequately equipped and staffed. At least 11 states have no drug testing facility. ${ }^{[19]}$ Academic institutions (both pharmacy and medical colleges) with advanced well-equipped testing laboratories offer a ray of hope in India. There are 132 approved postgraduate education and research institutions in pharmacy. ${ }^{[20]}$ These institutions can be established as quality-testing centers in collaboration with the regulatory agency. Likewise, bioequivalence testing facilities can be initiated in those institutions that have clinical facilities, e.g., the National Bioavailability Center (NBC) at the National Institute for Pharmaceutical Education and Research (NIPER), Chandigarh and the Ph.D Pharmaceutical Medicine program at Jamia Hamdard, New Delhi. The center at NIPER is accredited by WHO and is one of the two centers in the world recognized for conducting bioequivalence studies of fixed-dose combinations of antitubercular drugs, whereas the Pharmaceutical Medicine program at Jamia Hamdard is one of its specialized programs, where most research projects are based on bioavailability, bioequivalence, and drug interaction studies, etc. in healthy volunteers. In November 2006, the Chemical, Fertilizer, and Steel ministry announced the setting up of five more NIPER-like institutes in the metro cities of India.

All these efforts and the availability of sufficient infrastructure can ensure stringent regulation and improved vigilance over the quality of pharmaceuticals. Nigeria is an example of a country that is successfully fighting the problem of counterfeit drugs and looking to eradicate it altogether.

Azhar Yaqoob Khan, Naushad M. Khan Ghilzai* Department of Pharmaceutical Medicine,

Faculty of Pharmacy, Jamia Hamdard, N ew Delhi - 110 062, India. *D epartment of Pharmaceutical Sciences, LECO M School of Pharmacy, 1858 W Grandview Blvd, Erie, PA, 16509 USA. E-mail: azharykhan@yahoo.com

\section{References}

1. Charatan F. Fake prescription drugs are flooding the United States. BMJ 2001;322:1443.

2. Schofield J. Counterfeit pharmaceuticals flood Russian market. BMJ 2001;322:1564.

3. Wechsler J. Counterfeiting, compliance and control. Pharm Tech 2003; Vol no missing:28-36.

4. Menkes DB. Hazardous drugs in developing countries. BMJ 1997;315:1557-8.

5. Taylor RB, Shakoor O, Behrens RH. Drug quality, a contributor to drug resistance? Lancet 1995;346:122.

6. Costello AM, Bhutta TI. Antidiarrhoeal drugs for acute diarrhoea in children: None work and many may be dangerous. BMJ 1992;304:1-2.

7. English M, Marsh V, Amukoye E, Lowe B, Murphy S, Marsh K. Chronic salicylate poisoning and severe malaria. Lancet 1996;347:1736-7.

8. Taylor RB, Shakoor O, Behrens RH, Everard M, Low AS, Wangboonskul J, et al. Pharmacopoeial quality of drugs supplied by Nigerian pharmacies. Lancet 2001;357:1933-6.

9. Fleck F. WHO pulls two generic AIDS drugs from approved list. BMJ 2004;328:1518.

10. Odeniyl MA, Adegoke OA, Adereti RB, Odeku OA, Itiola OA. Comparative analysis of eight brands of sulfadoxine-pyrimethamine tablets. Trop J Pharm Res 2003;2:161-7.

11. Newton PN, Proux S, Green M, Smithuis F, Rozendaal J, Prakongpan S, et al. Fake artesunate in southeast Asia. Lancet 2001;357:194850.

12. Pincock S. WHO tries to tackle problem of counterfeit medicines in Asia. BMJ 2003;327:1126.

13. Guidelines for the development of measures to combat counterfeit drugs. WHO: Geneva, Switzerland; 1999.

14. Parry J. WHO combats counterfeit malaria drugs in Asia. BMJ 2005;330:1044.

15. Report of pre eleventh ICDRA satellite workshop on counterfeit drugs, 13 and 14 February 2004, Madrid, Spain.

16. Burns W. WHO launches taskforce to fight counterfeit drugs. Bull World Health Organ 2006;84:689-90.

17. A study on availability and prices of medicines in India. National Pharmaceutical Pricing Authority, Ministry of Chemicals and Fertilizers, Govt. of India. 2002. [Last accessed on 2006 Dec 31]. Available from: http://nppaindia.nic/report/voicerep. html.

18. Mashelkar Committee Report. Ministry of Health and Family Welfare, Government of India. August 2003.

19. Mudur G. India to introduce death penalty for peddling fake drugs. BMJ 2003;327:414.

20. List of Approved Post Graduate Education and Research institutions. All India Council of Technical Education, Govt. of India. September 2004. [Last accessed on 2006 Dec

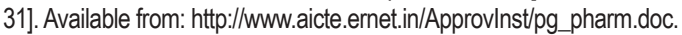

